Article

\title{
Re-Thinking Housing: From Physical Manifestation of Colonial Planning Policy to Community-Focused Networks
}

\author{
Shelagh McCartney \\ School of Urban and Regional Planning, Ryerson University, Toronto, ON M5B 2K3, Canada; \\ E-Mail: shelagh.mccartney@ryerson.ca
}

Submitted: 31 August 2016 | Accepted: 6 November 2016 | Published: 2 December 2016

\begin{abstract}
Current housing systems and policies for First Nations communities in Canada produce a physical manifestation of ongoing colonialism: the house. Examinations of the physical community and house yield an understanding of deeply systematized imperial struggles between Indigenous communities and planning as a discipline. Indigenous families are in crisis as the housing system and Federal planning policies have not allowed for the provision of adequate nor appropriate homes. The recent independent Truth and Reconciliation Commission has begun a civic discussion, accompanied by a new federal government looking to begin a new relationship with Indigenous peoples-here we explore how planning can be a leader in this shift. The 'contact zone' is used as an operational lens to examine the ways discourse is used to shape the existing housing system. An interdisciplinary and global approach informs interventions in the existing housing system and policies, creating a community-driven model, and uncovering a reimagined role for the planner.
\end{abstract}

\section{Keywords}

Aboriginal; development planning; First Nations; housing; inclusive and sustainable development; Indigenous planning; participatory planning; spatial planning

Issue

This article is part of the issue "Paradigm Shifts in Urban Planning", edited by Matthias Drilling (University of Applied Sciences and Arts Northwestern Switzerland, Switzerland), Efrat Eizenberg (Israel Institute of Technology, Israel), Janet Stanley (University of Melbourne, Australia), Lee Boon Thong (Nilai University, Malaysia) and Andreas Wesener (Lincoln University Canterbury, New Zealand).

(C) 2016 by the author; licensee Cogitatio (Lisbon, Portugal). This article is licensed under a Creative Commons Attribution 4.0 International License (CC BY).

\section{Introduction}

The independent Truth and Reconciliation Commission's Calls to Action, as well as the most recent federal election have brought discussion of a 'new relationship' (Liberal Party of Canada, 2015) with Indigenous peoples to the fore of public discussion in Canada. Indigenous peoples in Canada currently live with inequitably low funding and programming in education and health (Office of the Chief Coroner, 2016), and Indigenous youth are disproportionately being made wards of the state through "inequitable and discriminatory provision of child welfare services" (First Nations Child and Family Caring Society of Canada et al. v. Attorney General of Canada, 2016, p. 2). Numerous inquests, court cases, and policy documents recog- nize the link between poor housing, mental and physical health outcome gaps, and the ongoing crisis of Indigenous youth suicide (Finlay, Hardy, Morris, \& Nagy, 2010; Mushkegowuk Council, 2016; Standing Senate Committee on Aboriginal Peoples, 2015; Truth and Reconciliation Commission of Canada, 2015). Housing deficiencies in onreserve First Nations communities are alarming; rates of crowding are seven times the national average-a housing shortage that is forcing community members off reserves. Forty-three percent of homes are in need of major repair because of mold, fire, and structural damage (Statistics Canada, 2015), and "housing problems are most acute in remote communities" (Standing Senate Committee on Aboriginal Peoples, 2015, p. 4). These remote communities, the subject of this article, make up the majority of set- 
tlements across the mid-Canada corridor (see Figure 1), an east-to-west band across many provinces and territories loosely defined by the limits of the boreal forest. A culturally diverse area, the mid-Canada corridor is most commonly associated with its "treasure house of natural resources" (Rohmer, 1969, p. 1), not its people, owing to its vast separation from the densely populated, urban concentrations of power in Canada.

The link between the current housing system and community health crises is rarely analyzed through the lens of planning and its processes. The housing crisis facing Canada's Indigenous population is the physical manifestation of the continued implementation of assimilative policies of Canada's federal government, from the Gradual Civilization Act through to the Indian Act. Colonialism forced the relocation of Indigenous peoples to reserves and severed communities from their traditional land, while removing Indigenous children from their homes to reside in residential schools disintegrated traditions, language, and culture. Reserves became sites of 'suburban' community layouts, with houses not constructed to meet climactic demands and with no relationship to Indigenous culture or values. Cultural dislocation itself is understood to create the illness, depression, substance abuse, violence, and suicide found in so many communities (Kirmayer, Brass, \& Tait, 2000). Land use planning, as a discipline, has been complicit in Canada's imperialist objectives, facilitating both a constant expansion of territory and an imposition of Western values. The physicality and essential nature of housing makes it the perfect unit of analysis through which to understand planning's relation- ship with Indigenous peoples. The paradigm shifts needed to create a culturally appropriate, wellness-promoting housing system for remote and isolated First Nations communities in the mid-Canada corridor becomes part of the reconciliation project currently underway.

For more than half a century, Canada's federal government has recognized its failure in housing policy for Indigenous peoples (Carter, 1993) - a problem it continues to acknowledge through various reports, commissions, and hearings (Indian and Northern Affairs Canada, 1990; Royal Commission on Aboriginal Peoples, 1996; Standing Senate Committee on Aboriginal Peoples, 2015). But improvements in outcomes have not occurred (Office of the Auditor General [OAG], 2006, 2011). Consistently, the government has relied on a series of ad-hoc solutions; "short-term, crisis oriented initiatives that respond to a specific problem" (Carter, 1993, p. 6) but do not reconsider the housing system holistically. Periodically, specific 'symptoms' of poor housing, such as health, crime, or 'morality,' attract mainstream attention and a push is made to systemize a new level of adequacy that reflects the societal 'concern of the day' but neglects the assimilative principles that the system is built upon.

The house is a powerful cultural tool, and housing systems should not be reduced to only the creation of shelter or isolated dwelling units, but must be considered as part of a complex network of community assets. This conceptualization of housing is not unique to either the Western or First Nations traditions (Royal Commission on Aboriginal Peoples, 1996). While it is known that no homogenous culture exists across the many Nations

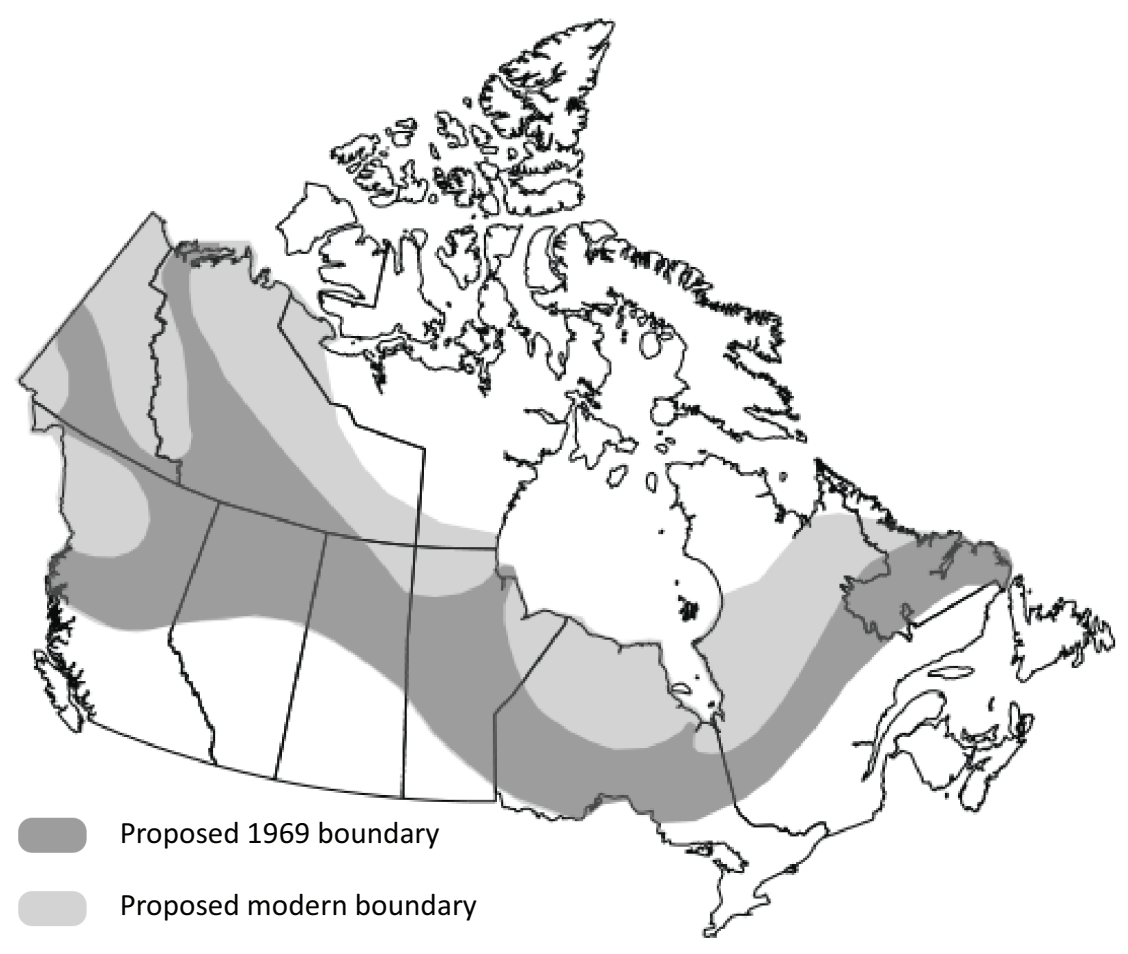

Figure 1. Mid-Canada Corridor. Diagram of Canada adapted from the 1969 concept of the Mid-Canada Corridor (Rohmer, 1969) and its modern re-imagining to include newly discovered resource rich areas (Van Nostrand, 2014). 
of Indigenous peoples throughout the vast near-north of Canada being examined in this paper, the Tsimshian of Central British Columbia provide one example of housing concepts among Indigenous communities: they understand housing as a "literal as well as symbolic seat of culture" (Perry, 2003, p. 603).

The Indian Act, enacted just after Confederation in 1866, remains an active destructive force in lives of Indigenous peoples within Canada. The aim of this policy, as described by former deputy superintendent of Indian Affairs, Duncan Campbell Scott, was "to continue until there is a not a single Indian in Canada that has not been absorbed into the body politic" (Indian and Northern Affairs Canada, 1978, p. 114). Housing inevitably became a powerful site of Canada's assimilationist project: As cultural superiority was assumed, the house became a tool through which to assert force. A standard housing regime was created that characterized Indigenous people as homogenous and needing to change, and culminated in a rigid urban structure, steeped in Western cultural norms, "grid patterns reminiscent of city subdivisions" (Ross, 2006, p. 120) that was manufactured across mid-Canada, ignorant to local culture, ways of living, and geography (see Figure 2 for an example).

Reimagining housing systems as value-driven equitable networks within communities requires the deconstruction of the colonial structures that support the existing system. To do this, the unique role of the planner must be recognized. The planner acts as an intermediary, implementing policy constructed by the settler state for Indigenous people-an interaction managed by power relationships. In seeking change, this paper focuses on interventions that can alter these interactions and processes, and how such changes would project onto the built environment. Planning's critical role of implementation in the housing system, together with the discipline's modern theoretical potential as emancipator (Ugarte, 2014) and provider of hope (Forester, 1982), provides an opportunity for planners to be leaders in building a new relationship and championing change with Indigenous communities.

This paper begins by examining the historical context through which housing policy has developed, and the existing policies governing development in First Nations communities across Canada's near-north. Informed by international anti-colonial thought including but not limited to planning literature we seek alternative conceptualizations of relationships in the development and implementation of housing policy in Canada. Indigenous voices and understandings are put in the center of this process to demonstrate a radically different approach to land, its use, and its regulation. This paper does not suggest one large-scale policy revolution to erase the impact of colonial land use policy on housing in remote Indigenous communities; rather, it explores paradigm shifts that can be made within the planning process that can spark the process of decolonization.

\section{Frontiers and Contact Zone}

Capitalizing on the role of the planner in the implementation of housing systems, we sought possible in-

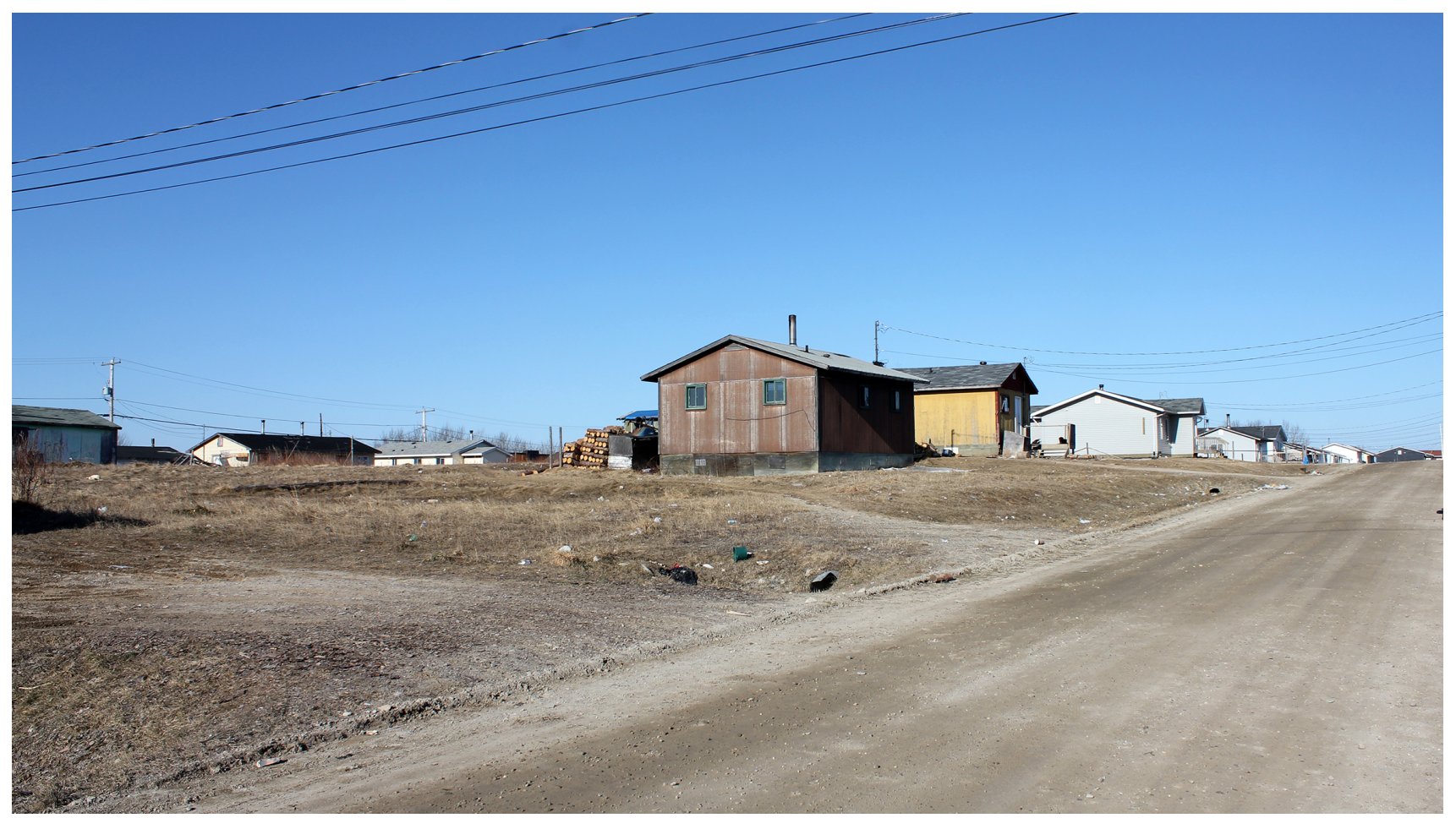

Figure 2. Eabametoong First Nation. Typical 'suburban' streetscape of a mid-Canada corridor First Nations community. Source: Author. 
terventions not at the policy level, but in the processes of engagement. A frame of analysis was required to understand how such disruptions could be projected onto the built environment and we adopted the concept of the 'contact zone,' a space, both physical and perceived, in which planning processes take place (Barry \& Porter, 2011). First conceptualized by Mary Louise Pratt (1991, 1992), the contact zone is a place of meeting and conflict between cultures. Equality is not presupposed within the contact zone and interactions often proceed "in [the] context of highly asymmetrical relations of power" (Pratt, 1991, p. 34). Acknowledging the context of power inherent in (post)colonial relationships situates the planning process within a historically accurate conceptual framework.

The contact zone is the place where the state, and those acting on its behalf, meet Indigenous peoples. Discourse is highly mediated and codified in policy; roles and responsibilities are strictly prescribed. Housing's physical form is a reflection of this discourse, transposing the dominant values onto the built form. Barry and Porter (2011) importantly understand the contact zones as, "contested sites that have both transformative and oppressive possibilities" (p. 173). Disruptions at the level of implementation have the potential to realign discourse within the contact zone-shifting power or reassigning responsibilities, creating wholly new outcomes. Interventions do not create new contact zones because interactions retain their historical context (Pratt, 1991), but they allow for the creation of a radically different product. The creation of a culturally appropriate built form requires a decolonization of the housing system, but does not require it to begin with policy.

Razack (2015) and Furniss (1999) explain the use of power within the contact zone of Indigenous/Settler relations is controlled by the frontier myth. These authors build on a series of metaphors and symbols described in the work of Richard Slotkin (1973), combining the cultural historical ideas of a tabula rasa North America, and Indigenous peoples being brought into a civilized state by European settlers. In Canada, the frontier is understood as, "marked by boundaries and the encounter of opposites: civilization and savagery, man and nature, whites and Indians, good and evil" (Furniss, 1999, p. 198). The Western planning tradition, founded in a Euclidean pursuit of order and stability (Friedmann, 1993), serves to further the myth of 'civilizing' (and thereby destroying Indigenous cultural practices), but can be reoriented towards action. Existing housing frameworks and interventions are examined in this paper to clarify how implementation processes, and the assumptions that uphold them, are projected onto the built environment.

\section{Planning's Complicity in Cultural Erasure}

Different treaty histories, points of contact, and levels of economic, government, and religious coercion have created distinct colonial legacies across Canada. Broadly,
First Nations peoples living in the communities across the mid-Canada corridor encountered much later direct government intervention-beginning only in the early twentieth century-than those in first colonized areas adjacent to the St. Lawrence Seaway and the Great Lakes of southern Canada. Before government intervention, settler influence was already occurring through the Hudson's Bay Company, established in 1670, whose trade was accompanied by the spread of disease, over-hunting, and trapping. When direct government intervention did arrive in the mid-Canada corridor, its land use processes were informed by the previous two centuries of development across southern Canada. Understanding the housing policies introduced in these communities over the last half-century requires an understanding of the historical attitudes that led to their development.

Canada's federal government has inherited a unique jurisdictional position in First Nations communities, founded in The Royal Proclamation of 1763, with the first tripartite agreement between the British Crown, Canadian Colony, and Indigenous peoples. Land sovereignty was already a question in the 18th century, and the agreement established that Indigenous peoples had preexisting rights to land in the establishing Canadian colony, but installed the Crown as "protector of Indian people, particularly in matters involving land" (Indian and Northern Affairs Canada, 1978, p. 5). Procedures were enumerated for acquiring land by settlers or the colony. A sense of benevolence saw the Crown assume responsibility until it deemed First Nations people, "were able to occupy and protect them [the lands] in the same way as other citizens" (Indian and Northern Affairs Canada, 1978, p. 1). The conception of a nation-to-nation relationship was born from the Proclamation, and with it, land rights that could not be extinguished. But also born was enduring inequality in land-use decisions.

As settler populations grew, and risk of war with the United States subsided with the 1814 Treaty of Ghent, the Crown's impetus for relationship-building to create military allies of Indigenous peoples diminished. "Other aspects of British Indian Policy such as civilization and protection became more prominent" (Indian and Northern Affairs Canada, 1978, p. 12) meaning that the full impetus of the Crown's perceived superiority could now be implemented in policy. Peacetime, and a focus on the economic development of the home front, pushed the expansion of empire westward and northward. Satisfying newly arriving settlers, Miller (2001) argues, meant the existing methods of acquiring land through statutory provisions and consent of Indigenous peoples were seen as prohibitively time-consuming and costly; Indigenous peoples were now an "expensive encumbrance and an obstacle to agricultural expansion" (p. 118).

The dominant belief in the mid-nineteenth century was that "only by isolating Indians on reserves, could the resident school teacher, agent and missionary achieve success in preparing Indians for integration" (Indian and Northern Affairs Canada, 1978, p. 16). The reserve sys- 
tem provided a land-use plan that enforced these transitional spaces. The project of assimilation, jointly undertaken by government, church, and business, required the destruction of all cultural practices in these spaces. Reserves tied First Nations communities to a particular land-base, enforcing where possible agrarian economies similar to those practiced by settlers, while making available large tracts of land (Monk, 2006). On-reserve housing completely re-ordered domestic life by altering family structures, normalizing gender roles, and providing a basic economic unit, housing design served a clear colonial moralizing agenda, which recognized that "there is no better teaching tool than the object of a good wellordered Christian home" (Perry, 2003, p. 594).

The discovery of gold in the Yukon Territory and other minerals in Northern Ontario and Saskatchewan pushed the frontier and its land-use processes into the midCanada corridor between 1899 and 1907 with the signing of Treaties Eight, Nine, and Ten. Roy (2006) argues that planning became complicit in the project of empire, not through warfare but through the narrative of progress. The tools of the planner facilitated economic expansion and resource extraction; building, surveying, mapping, and development became the weapons with which the frontier was conquered. As the political tool accompanying the ordering and division of land, the treaty process had already established a pattern of dispossession and broken promises (Buckley, 1992). Despite the already dismal conditions of First Nations peoples in the mid-Canada corridor, legacies of colonial economic forces meant that Indigenous inhabitants who thought the treaties brought "a relationship of friendship and mutual assistance with the government, were shocked by the treatment they received" (Miller, 2001, p. 204).

During this period of territorial expansion, the Indian Act was transforming as well. What was formerly outlined as "protection slid into interference, persuasion was dropped for aggressive efforts to redirect cultural practices" (Miller, 2001, p. 206). Formal policy was shifting engagement with Indigenous communities; the contact zone had become a place of aggression. Settler growth required a policy focus on dispossession. Frank Oliver, then Minister of the Interior stated, "there are certain circumstances and conditions in which the Indian by standing on his treaty rights does himself an ultimate injury, as well as does an injury to the white people, whose interests are brought into immediate conjunction with interest of the Indians" (Indian and Northern Affairs Canada, 1978, p. 109). Power was codified to ensure an 'orderly' use of land in which productivity and the economically efficient use of land superseded Indigenous rights and interests (King, 2010; Porter \& Barry, 2015).

\section{Direct Housing Intervention in First Nations Communities of the Mid-Canada Corridor}

After World War II, government attention began to focus on social responsibility for all Canadians. The Curtis Re- port explained that Canada had fallen behind other Western states in "providing greater governmental assistance for housing as a matter of welfare and public concern" (Advisory Committee on Reconstruction, 1944, p. 9), and assigned housing systems an important role in the development of a social welfare agenda. Development programs in this period, the 1944 National Housing Act and the creation of the Central Mortgage and Housing Corporation $(\mathrm{CMHC})$ created national bodies capable of largescale poverty alleviation projects.

In the 1950-60s, the emerging national sense of social responsibility drove government to the remote First Nations communities of the mid-Canada corridor and the far north. The introduction of government services including family allowance, day schools, and increased health services forcibly changed living patterns (Carter, 1993). Families were told that in order to collect welfare payments and receive services they must live permanently at service points (Carter, 1993; Ross, 2006). The first housing system stemmed from a program of coerced settlement (Deirmenjian \& Jones, 1983), requiring the building of many units to meet the new demand.

The government supplied houses nationally through the so-called Crash Housing Program; units were standardized and basic, intended only as a temporary solution to bring local residents up to an adequate standard of living. Immediately, however, the housing was recognized as "being too small, the sanitation facilities inadequate, the quality of construction poor and the method of heating inappropriate" (Carter, 1993, p. 13). Units had been provided to mid-Canada corridor First Nations communities in line with the national concern for social responsibility, but served only to exacerbate the conditions of substandard housing and health (Thompson \& Thompson, 1972). The Crash Housing Program was the first in a series of national "ad hoc, short-term, crisis-oriented initiatives" (Carter, 1993, p. 6) formalized in the mid-1960s that brought southern-Canadian based housing designs and concepts north, as a means of establishing a national level of adequacy. The result was the loss of local, culturally-specific housing designs in favor of a 'suburban' model being implemented across Canada for its efficiency and affordability (Royal Commission on Aboriginal Peoples, 1996, S.4.2.1) "in ignorance of the economic, psychological and physical reality" (Ross, 2006, p. 120).

The current policy, the 1996 On-Reserve Housing Policy, is only the second formal housing policy for First Nations communities. Developed in response to the "limited range of housing designs and technologies" (Indian and Northern Affairs Canada, 1990, p. 6) on reserve, it recognizes "the principle that First Nations should have meaningful control over their own housing programs" (Indian and Northern Affairs Canada, 1990, p. 17). Monk (2006) states that the policy was championed by the federal government for its increased flexibility, tying funding to long-term planning initiatives developed locally rather than specific projects. A significant shift from a centrally controlled policy of national equality and standardiza- 
tion, the four stated principles here were: First Nations control, First Nations expertise, shared responsibilities, and increased access to private sector financing.

Despite recognizing the importance of First Nations control of housing, a 2011 evaluation of the policy revealed that it, and its accompanying programs, "did not adequately incorporate a First Nations' perspective and was poorly communicated to First Nations" (OAG, 2011). Downloading control was not accompanied by the requisite resources to develop the capacity or plans required to create localized systems, thus undercutting any chance the policy may have had at success (OAG, 2011, 2015). Continued poor housing conditions illustrate the policy's ineffectiveness. Auditor General reviews in both 2008 and 2011 were skeptical of any significant improvements noting, "results have not kept pace with housing needs" (OAG, 2011). Despite the focus on flexibility, the policy amounts to a shifting of burden, nominally moving control to First Nations without the required investment. Funding, and with it power, remain centrally controlled by the federal government and the focus on homeownership and private lending markets ignores the nonmarket economies of remote mid-Canada corridor First Nations communities, showing a continued reliance on inappropriate southern-Canadian models for solutions.

\section{Conceptual Rifts in Planning: Indigenous Worldviews in the Contact Zone}

Western planning negated other worldviews in the early twentieth century due to its reliance on a rational economic model that followed broader cultural shifts of the time. Ted Jojola (2013) asserts that one ramification of the assumed dominance of this model is that, "there is very little written about the ethical, methodological, and epistemological approaches to community design and planning by Indigenous communities" (p. 457). Although forms of land use that counter and predate the dominant discourse of order and efficiency may have been ignored, they are not lost.

To control the existing housing provision system and dominate the land use regime, planning has relied on two main tools: assertions of authority through an essentializing of technical knowledge, and a tokenism in participation created through liberalisms' mechanism of recognition. These tools, while supported by dominant ideologies have not always been enshrined in policy, but have instead relied on a maintenance of the status quo through planning's implementation process. Power continues to be asserted methodologically by understanding that "land and 'resources' are seen in a utilitarian light" (King, 2010). The standardized existing built form demonstrates that "the technology adopted in many cases was based on industrial building systems in the hope that the rationale of factory and industrial production will lead to more efficient housing production and lower costs" (Keivani \& Werna, 2001, p. 85). Alternative theoretical models rooted in local cultures exist, however, and counter the drive for efficiency and cultural assimilation that would produce vastly different housing systems.

\subsection{Indigenous Planning}

Planning theorists from radical and anti-colonial perspectives are establishing a literature of Indigenous Planning, focused on community-level values (see for example, Jojola, 2008, 2013) instead of state-based solutions (Hibbard \& Lane, 2004). Decolonization of the planning process is only possible through a "complex renegotiation of values, knowledge meaning, agency and power between planning and Indigenous peoples" (Porter, 2010, p. 153). The impetus to begin a decolonization process starts with a recognition of planning's involvement in the marginalization of Indigenous communities and a questioning of "established normative assumptions of planning's role in bettering the world" (Ugarte, 2014, p. 153). Recognition is required that the existing Western rational model does not fulfill the discipline's ethical requirement to justice and future-based practice (Friedmann, 2002). The reiterations of critical planning processes search for ways to make planning a "positive site for the exercise of Indigenous self-determination" (Barry \& Porter, 2011, p. 173).

The role of Indigenous communities in the planning process provides one site of potential change. Instead of prioritizing Indigenous values, the nominal recognition and control that accompanied the 1996 On-Reserve Housing Policy had the effect of subjugating and compartmentalizing Indigenous interests (King, 2010; Rankin, 2010; Sandercock, 2004), acting as a form of "internal colonization" (Hibbard \& Lane, 2004, p. 98). Shifting from the more overt colonial tactic of civilizing through forcible changes, participation in the planning processes is "couched in the vernacular of mutual recognition" (Coulthard, 2007, p. 438). But as Alfred and Corntassel (2005) argue, participation without any fiscal controls or an overturning of existing power structures serves only as a "distraction that diverts energies away from decolonizing and regenerating communities and frames community relationships in State-centric terms" (p. 600).

Indigenous planning advocates for models that are community-focused or space-based, and asserts that validity requires that "a community plan cannot be developed from the outside looking in" (Hibbard, Lane, \& Rasmussen, 2008; Mannell, Palermo, \& Smith, 2013, p. 122). Recognition therefore is not bestowed by the state, but is inherently held and asserted by local populations (Dorries, 2012). Shifting modes of recognition in the contact zone rejects the standardized approach applied to First Nations communities who are depicted as homogenous in policy, and instead highlights their uniqueness in values, visions, and goals.

The planner adopts a new role in an Indigenous ledhousing system. Rather than imposing a model aiming to create a national level of adequacy, the planner instead becomes a learner, adopting and sharing a model to meet local need (Lane, 2006; Rankin, 2010; Simp- 
son, 2001). The communicative nature of the contact zone allows for the planner to form relationships not possible at the policy level. Shifting discursive power allows the planner to become a conduit for Indigenous voices and disrupt imperial political regimes. Planning processes can be transformed from a place where hegemony is reproduced to one that recovers and centers Indigenous voices (Rankin, 2010). Projected onto the built environment, this implies that housing systems are not standardized engineering solutions, but are process, design, and technology solutions representative of individual communities.

Positioning the planner as a learner allows the contact zone to become the site where local housing needs, priorities, and preferences are enumerated. Contextspecific housing visions can then be created by individuals within a community, focused on their specific culture and needs. The planning process becomes decolonized when the housing system it develops creates sites of cultural regeneration. The Royal Commission on Aboriginal Peoples proposed in 1996 "that better housing and community services, as well as the processes and activities leading to them, will improve community morale and increase every individual's sense of self-worth and identity" (p. 348). Through a reflexive practice and focus on listening, planners can establish processes that result in appropriate housing where local housing needs, priorities, and preferences are enumerated and delivered. This paradigm shift would also create changes in Canada's Indigenous communities and their community health.

\subsection{Alternative Ways of Knowing}

Shifting participation is only valuable if changes also occur to what is considered valid and to substantive participation. Planners must give up their narrow focus on technocratic expertise, enlightenment scientific-rational thought, and economic efficiency-all textually based knowledge systems - and embrace the emancipatory potential of planning. Doing so would force reflexivity on the part of the planner. When working with a specific community, a planner cannot assume that their training has equipped them with knowledge or values that are similar to the population they are working with.

Leanne Simpson (2001) explains that "knowledge might come to us from relationships, from the Elders, oral traditions, experimentation, observations from our children, or our teachers in the plant and animal worlds" (p. 142). Contrasted against the rigidity of textual traditions, Simpson describes a more experiential and personal journey towards knowledge, which make take different forms across different cultures. This is a journey that Kurtz (2013) describes as self-discovery, and is part of a lifetime of learning and sharing.

The cultural specificity of knowledge creation prevents broad assumptions from being made about the effects of alternative ways of knowing in the contact zone. King (2010) illustrates one example through a cultural un- derstanding of land. He identifies the significant difference in understanding land innately as a part of holistic community wellness, rather than an asset to be managed, controlled, and developed. When land is the law around which society is governed, policies cannot be made to order and manage the land.

In the housing context, we can derive another example from The Royal Commission on Aboriginal Peoples (1996), which describes a past where Indigenous housing embodied local cultures. If cultural identity and community wellness are understood as a primary function of housing, rather than the pursuit of assimilation, poverty reduction, or disease control, we would be forced to assume a radically different discourse within the planning process. Recording and building to promote cultural identity and wellness would create a radically different built form.

Extracting local knowledge without first dismantling existing systems continues the frontier myth. Indigenous knowledge cannot be divorced from the systems that created it; knowledge removed from its contextual foundation is meaningless and entrenches power systems. An example in which Indigenous peoples enter a contact zone and share their knowledge in the existing Canadian development framework is through the Traditional Ecological Knowledge component of environmental assessments. It is understood that Elders hold information about the land, its history, and places on the land that are unique (King, 2010; Simpson, 2001). However, in documenting, digitizing, and incorporating this knowledge into a broader system, "researchers were not interested in all kinds of knowledge, and they remain specifically interested in knowledge that parallels the Western scientific discipline of ecology" (Simpson, 2001, p. 138) thus mirroring the reliance on empiricism throughout existing processes. Fitting this knowledge into the existing textual base requires a process of translations-a "recasting of others' way of putting things in terms of our own ways" (Geertz, 1983, p. 10). Recasting Indigenous knowledge, in particular, through a colonial lens creates ample opportunity for misuse, removing the knowledge from the community that produced it and continuing a cycle of Indigenous dispossession.

Decolonizing the contact zone sufficiently to allow for localized understandings requires dismantling a system in which "design, structure, and implementation are so steeped in technical language and procedure of bureaucracy that Indigenous peoples have immense difficulty accessing of participating in them in earnest" (King, 2010, p. 79). This decolonization implies a shift in the burden of the planning process from community participant to planner. The contact zone is currently controlled by one knowledge system, thus demanding a fluency on the part of Indigenous peoples as a basis for participation. The planner can reject sole authority through textual knowledge, understand the existence of a local knowledge system, and assume the burden of reorienting their values to create contextual meaning for the processes being undertaken. 
Many models to include Indigenous knowledge are described in the literature of various disciplines (Calliou, 2015; Jojola, 2013; Kurtz, 2013), each serving as a reminder that the rational-scientific model currently given preference has alternatives. The alternative models demonstrate the possibility of rejecting the idea that housing is a problem solely of health, poverty, or design that must be solved through science. Instead, diversity can be brought to the built form of the house and community, representing the diversity of understandings present within communities. Physical forms will shift as the housing system comes to represent local knowledge structures, and the houses and the landscapes between them that are created will be embodiments of the Jojola's (2013) assertion that "culture is not a fad, it is a way of life" (p. 465).

\subsection{Learning from the Global South}

Participatory processes valuing local knowledge and identity are beginning to take hold in Global South housing provision systems. The Global South is a site where the body politic has, in some situations, been effective in using political pressure to address issues of poverty, moving policy beyond centralized planning towards holistic comprehensive models. Housing is no longer being thought of as either a problem of poverty that can be solved through the generosity of the state, or a problem of economics that the market should be relied upon for solutions. Rather, housing is being viewed as a problem of equity affecting and affected by a wide series of variables. Housing, as already demonstrated, is a manifestation or symptom of the systems that create it. Harris (2015) wrote, "What matters more than physical conditions are the processes that produced, and still shape, them" (p. 122).

Large international governmental and aid agencies, traditionally reliant on neo-liberal and market-based solutions, have begun "joining environmental, social and economic development in housing" (Pugh, 2001, p. 408). Angel (2000) summarized these changes as place-based solutions that require, and are improved by, a variety of state, local, and non-governmental actors. According to a World Bank policy, localization and working with local agencies comes with "less certitude" (Buckley \& Kalarickal, 2006, p. viii), or what is elsewhere described as "a subtler, messier, more balanced approach" (Harris, 2015, p. 129). Rigidity and generalizations are being dropped for more complex nuanced solutions. United Nations programs now include slum resident surveys, and the World Bank values flexibility recognizing, as Indigenous planning does, that solutions must be community-based.

The shift towards place-based, holistic-systems approaches in housing provision systems also signals a move away from understanding houses in isolation. Changing the scale of housing intervention from the unit to the community forces the context of a house to be considered. As Belsky et al. (2013) explain, this also changes the time horizon of the housing process; rather than oneoff project-to-project approaches, a longer-term focus on learning local needs and preferences takes hold. The anticipatory nature of such an undertaking, sensitive to climate, demographics, and geography, requires a participatory process to facilitate the required knowledge creation. The projection onto the built form then comes to represent a process not managed or driven by individual programs but instead directed by values.

Belsky et al. (2013) develop the concept further, applying Caroline Moser's (1998) concept of asset building to housing. Housing provision systems here are understood as part of a complex calculation performed by each community, balancing their housing need against others, while maximizing existing skills and resources within the community. Notably, removing housing from a policy silo, and understanding its role within the larger community development framework allows the provisioning system to reinforce local development trajectories. Additionally, this flexibility not only permits housing to be a growing asset within the community but to develop local capacity-itself an asset. Housing provision then creates a reinforcing model developing both appropriate houses, and community members capable of managing the development and maintenance of the system.

\section{Decolonizing Planning: Change in the Canadian Regime}

Housing as it currently exists on-reserve in the midCanada corridor symbolizes planning's complicity in a colonial political regime. Through its processes planning continues to enact the assimilationist ideas of its earliest lawmakers. Reliance on technical, scientific knowledge and coercion through the language of participation has undermined Indigenous people from participating in the development of their housing. The dominant housing system is created on a model of economic efficiency, rationality and standardization, distributing across the country a uniform product to establish a level of Westerndefined adequacy at the expense of culture. The result has been a marginalization of Indigenous peoples facilitated by planning's continuation of the frontier myth in its implementation of federal policy.

Examples of community-based housing systems in Canada are sparse, in particular across the mid-Canada corridor where financial resources and access to power are limited. Peri-urban reserves, and off-reserve urban Indigenous people have gained increased attention, having their voices centered in housing discussions as local and regional planners shift away from their inclusion only as stakeholders (Metro Vancouver Aboriginal Executive Council, 2015; National Aboriginal Housing Association, 2009; Walker, 2005).

Oujé-Bougoumou, located in Northern Quebec, within the mid-Canada corridor is an example of a community and its partners building housing symbolic of a culture and its people. Having been forcibly relo- 
cated nine times over eighty-five years, the community reached separate agreements with the provincial and federal governments to establish and construct a new community. The development of the community, taking place over ten years was guided in discussion-, dreamingand visualization-sessions by three principles: to be constructed in harmony with the environment and the traditional Cree philosophy of conservation; provide for the long-term financial requirements of community members; and reflect the Cree culture in its physical appearance and function (Malnar \& Vodvarka, 2013). Despite setbacks from engineering flaws in individual houses, "the community was created for longevity; every decision was made by considering the requirements of future generations" (Stevens \& Reid, 1999, p. 8); the radial form and fluidity in lot shapes show clear, built-form distinctions from other mid-Canada corridor communities (see Figure 3). Under the special circumstances of this case, a radically different built form was created.

Centering Indigenous knowledge in the planning process can create a housing system supportive of cultural regeneration and increased community wellness. Implementation changes alone can only create incremental change; building new units differently and pro- jecting local understandings of culture and wellness are needed. Oujé-Bougoumou demonstrates that communities across the mid-Canada corridor require funding of a large magnitude to meet the existing scale of housing need and meet the goals of Reconciliation. Contact zone interventions break the cycle of colonialism, but colonialism's damage can only be undone by matching shifts in power with expenditure that allows new discourses to be projected widely onto the built environment. Deconstructing the rational model, and shifting towards Indigenous planning and ways of knowing would allow the discipline to become a leader in establishing a new relationship with Indigenous peoples in Canada and could result in the development of a model that policy can support and replicate across other disciplines.

\section{Acknowledgements}

The author would like to thank Jeffrey Herskovits and Dr. Judy Finlay for their support, belief in this project, and helpful comments. In addition, the communities of Eabametoong First Nation and Nibinamik First Nation, including their Chiefs Elizabeth Atlookan and Johnny Yellowhead, Elders, youth, and community members for

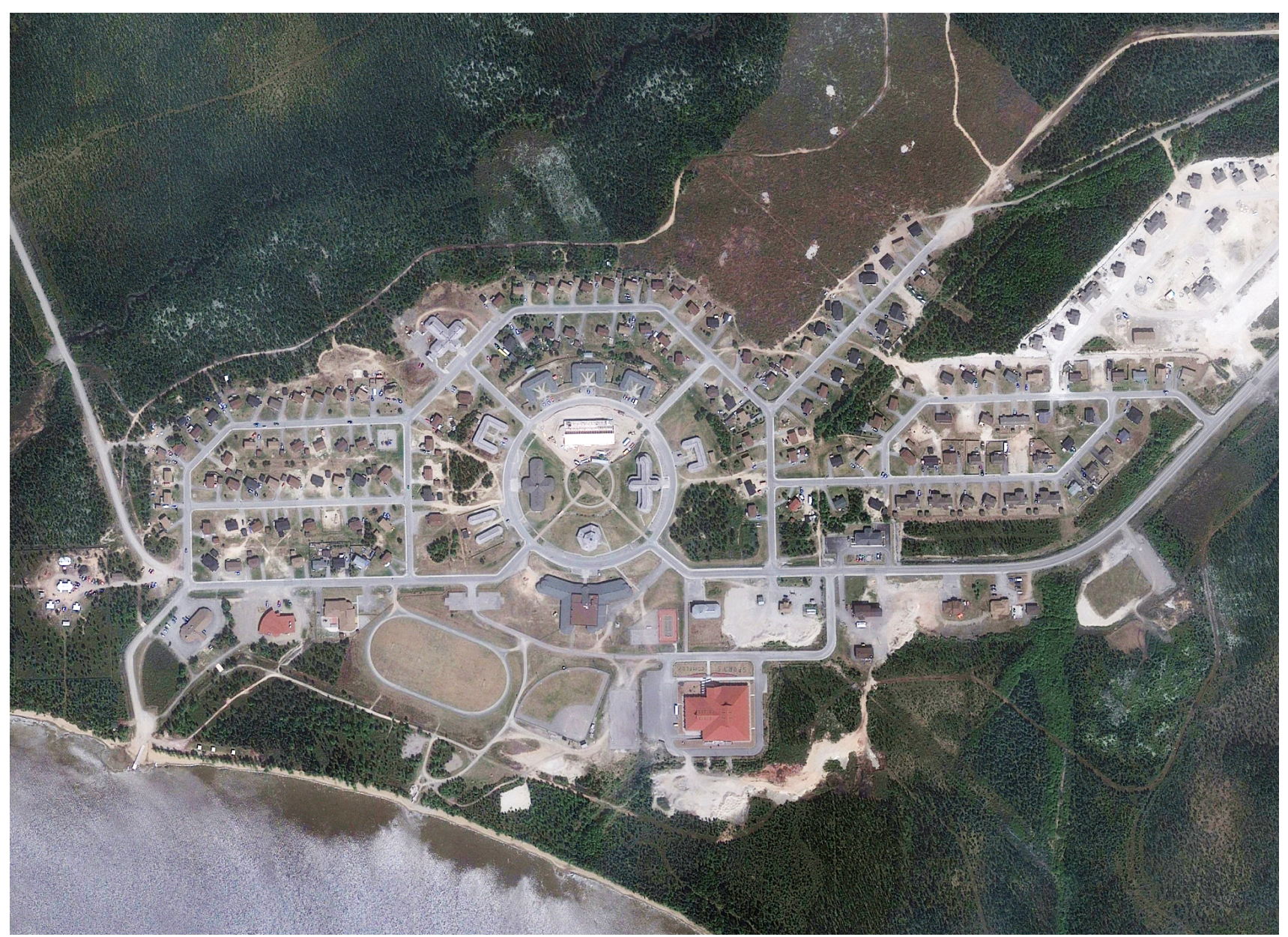

Figure 3. Oujé-Bougoumou, Quebec. Radial grid formed in the development of the new Oujé-Bougoumou community. Source: Author with base from Google Earth. 
their partnership and welcoming her into their homes and lives. Finally, the author wishes to thank the editors of this special issue and anonymous reviewers for their valuable feedback. This article is based on a research project supported by the Faculty of Community Services at Ryerson University and the Social Sciences and Humanities Research Council of Canada.

\section{Conflict of Interests}

The author declares no conflict of interests.

\section{References}

Advisory Committee on Reconstruction. (1944). Report IV: Housing and community planning: Final report of the subcommittee. Ottawa: King's Printer.

Alfred, T., \& Corntassel, J. (2005). Being Indigenous: Resurgences against contemporary colonialism. Government and Opposition, 40(4), 597-614.

Angel, S. (2000). Housing policy matters: A global analysis. New York: Oxford University Press.

Barry, J., \& Porter, L. (2011). Indigenous recognition in state-based planning systems: Understanding textual mediation in the contact zone. Planning Theory, 11(2), 170-187.

Belsky, E. S., DuBroff, N., McCue, D., Harris, C., McCartney, S., \& Molinsky, J. (2013). Advancing inclusive and sustainable urban development: Correcting planning failures and connecting communities to capital. Cambridge, MA: Joint Center for Housing Studies of Harvard University.

Buckley, H. (1992). From wooden ploughs to welfare: Why Indian policy failed in the Prairie Provinces. Montreal: McGill-Queen's University Press.

Buckley, R. M., \& Kalarickal, J. (2006). Thirty years of World Bank shelter lending: What have we learned? Washington, DC: The World Bank.

Caillou, B. (2015). Methodology for recording oral history in the Aboriginal community. In K. R. Llewellyn, A. Freund, \& N. Reilly (Eds.), Canadian oral history reader (pp. 25-52). Montreal: McGill-Queen's University Press.

Carter, T. (1993). Evolution of Northern housing policy. Winnipeg, MB: Institute of Urban Studies.

Coulthard, G. S. (2007). Subjects of empire: Indigenous peoples and the 'politics of recognition' in Canada. Contemporary Political Theory, 6, 437-460.

Deirmenjian, S., \& Jones, M. (1983). Planning for communities in the North: A preliminary evaluation of an innovative approach in the Northwest Territories. Toronto: Ryerson University.

Dorries, H. J. (2012). Rejecting the "False Choice": Foregrounding Indigenous sovereignty in planning theory and practice (Doctoral Dissertation). University of Toronto, Toronto, Ontario.

Finlay, J., Hardy, M., Morris, D., \& Nagy, A. (2010). Mamow Ki-ken-da-ma-win: A partnership approach to child, youth, family and community wellbeing. International Journal of Mental Health and Addiction, 8, 245-257.

First Nations Child and Family Caring Society of Canada et al. v. Attorney General of Canada 2016 CHRT 2 T1340/7008 (Canada).

Forester, J. (1982). Planning in the face of power. Journal of the American Planning Association, 48(1), 67-80.

Friedmann, J. (1993). Toward a non-Euclidian mode of planning. Journal of the American Planning Association, 59(4), 482-485.

Friedmann, J. (2002). The prospect of cities. Minneapolis: University of Minnesota Press.

Furniss, E. (1999). Indians, odysseys and vast, empty lands: The myth of the frontier in the Canadian justice system, Anthropologica, 41(2), 195-208.

Geertz, C. (1983). Local knowledge: Further essays in interpretive anthropology. New York: Basic Books.

Harris, R. (2015). International policy for urban housing markets in the Global South since 1945. In F. Miraftab \& N. Kudva (Eds.), Cities of the Global South reader (pp. 122-133). Hoboken: Taylor and Francis.

Hibbard, M., \& Lane, M. B. (2004). By the seat of your pants: Indigenous action and state response. Planning Theory \& Practice, 5(1), 97-104.

Hibbard, M., Lane M. B., \& Rasmussen, K. (2008). The split personality of planning: Indigenous peoples and planning or land and resource management. Journal of Planning Literature, 23(2), 136-151.

Indian and Northern Affairs Canada. (1978). The historical development of the Indian Act: Second edition. Ottawa: Treaties and Historical Research Centre, P.R.E. Group, Indian and Northern Affairs.

Indian and Northern Affairs Canada. (1990). Laying the foundations of a new on-reserve housing program (Discussion Paper). Ottawa: Indian and Northern Affairs Canada.

Jojola, T. (2008). Indigenous planning-An emerging context. Canadian Journal of Urban Research, 17(1), 37-47.

Jojola, T. (2013). Indigenous planning: Towards a seven generations model. In R. Walker, T. Jojola, \& D. Natcher (Eds.), Reclaiming Indigenous planning (pp. 113-140). Montreal: McGill-Queen's University Press.

Keivani, R., \& Werna, E. (2001). Modes of housing provision in developing countries. Progress in Planning, 55, 65-118.

King, H. (2010). Give it up: Land and resource management in the Canadian North. Illusions of Indigenous power and inclusion. In Canada's North: What's the plan? The 2010 CIBC scholar-in-residence lecture. Ottawa: The Conference Board of Canada.

Kirmayer, L. J., Brass, G., \& Tait, C. L. (2000). The mental health of Aboriginal peoples: Transformations of identity and community. Canadian Journal of Psychiatry, 45, 607-616.

Kurtz, D. (2013). Indigenous methodologies: Traversing 
Indigenous and Western worldviews in research. AlterNative: An International Journal of Indigenous Peoples, 9(13), 217-229.

Lane, M. B. (2006). The role of planning in achieving Indigenous land justice and community goals. Land Use Policy, 23, 385-394.

Liberal Party of Canada. (2015). Real Change. Retrieved from https://www.liberal.ca/realchange

Malnar, J. M., \& Vodvarka, F. (2013). New architecture on Indigenous lands. Minneapolis: University of Minnesota Press.

Mannell, L., Palermo, F., \& Smith, C. (2013). Community based and comprehensive: Reflections on planning and action in First Nations. In R. Walker, T. Jojola, \& D. Natcher (Eds.), Reclaiming Indigenous planning (pp. 113-140). Montreal: McGill-Queen's University Press.

Miller, J. R. (2001). Skyscrapers hide the heavens: A history of Indian-White relations in Canada (3rd ed.). Toronto: University of Toronto Press.

Monk, L. (2006). Decolonizing home: A re-conceptualization of First Nations' housing in Canada (Thesis). Queen's University, Kingston, Ontario.

Moser, C. (1998). The asset vulnerability framework: Reassessing urban poverty reduction strategies. World Development, 26(1), 1-19.

Mushkegowuk Council. (2016). Nobody wants to die. They want to stop the pain: The people's inquiry into our suicide pandemic. Retrieved from http:// peoplesinquiry.com/thepeoplesinquiry

Metro Vancouver Aboriginal Executive Council. (2015). Towards an urban Aboriginal housing and wellness strategy for Metro Vancouver: 2015-2020. Retrieved from http://www.mvaec.ca/downloads/uahws-fullreport.pdf

National Aboriginal Housing Association. (2009). A time for action: A national plan to address Aboriginal housing. Retrieved from http://www.ontarioaborigi nalhousing.ca/wp-content/uploads/2014/09/NAHA_ Action_Plan_July_2009_FINAL.pdf

Office of the Auditor General. (2006). Report to the Auditor General of Canada: Chapter 5-Management of programs for First Nations. Ottawa: Office of the Auditor General.

Office of the Auditor General. (2011). Report of the Auditor General to the House of Commons: Chapter 4Programs for First Nations on reserves. Ottawa: Office of the Auditor General.

Office of the Chief Coroner. (2016). Jury recommendations based on Thunder Bay Inquest. Retrieved from http://www.nan.on.ca/upload/documents/jury-ver dict-and-recommendations.pdf

Perry, A. (2003). From 'the hot bed of vice' to the 'good and well-ordered Christian home': First Nations housing reform in nineteenth-century British Columbia. Ethnohistory, 50(4), 587-610.

Porter, L. (2010). Unlearning the colonial cultures of planning. Farnham: Ashgate Publishing Limited.
Porter, L., \& Barry, J. (2015). Bounded recognition: Urban planning and the textual mediation of Indigenous rights in Canada and Australia. Critical Policy Studies, 9, 22-40.

Pratt, M. L. (1991). The Arts of the Contact Zone. Profession, 91, 31-40.

Pratt, M. L. (1992). Imperial eyes: Travel writing and transculturation. New York: Routledge.

Pugh, C. (2001). The theory and practice of housing sector development for developing countries, 1950-99. Housing Studies, 16(4), 399-423.

Rankin, K. N. (2010). Reflexivity and post-colonial critique: Toward an ethics of accountability in planning praxis. Planning Theory, 9(3), 181-199.

Razack, S. (2015). Dying from improvement: Inquests and inquiries into Indigenous deaths in custody. Toronto: University of Toronto Press.

Rohmer, R. (1969). Mid-Canada development corridor: A concept. Toronto: Acres Research and Planning limited.

Ross, R. (2006). Dancing with a ghost: Exploring Aboriginal reality. Toronto: Penguin Canada.

Roy, A. (2006). Praxis in the time of empire. Planning Theory, 5(1), 7-29.

Royal Commission on Aboriginal Peoples. (1996). Report of the Royal Commission on Aboriginal peoples. Ottawa: The Commission.

Sandercock, L. (2004). Indigenous planning and the burden of colonialism. Planning Theory \& Practice, 5(1), 118-124.

Simpson, L. (2001). Aboriginal peoples and knowledge: Decolonizing our processes. The Canadian Journal of Native Studies, 21(1), 137-148.

Slotkin, R. (1973). Regeneration through violence: The mythology of American frontier, 1600-1800. Middleton, CT: Wesleyan University Press.

Standing Senate Committee on Aboriginal Peoples. (2015). On-reserve housing and infrastructure: Recommendations for change. Ottawa: The Senate of Canada.

Statistics Canada. (2015). Housing Conditions. Retrieved from http://www.statcan.gc.ca/pub/89-645x/2015001/housing-logement-eng.htm

Stevens, C., \& Reid, J. A. (1999). Building sovereignty: The architectural sources of Oujé-Bougoumou. Canadian Issues, 21, 124-142.

Thompson, D. K., \& Thompson, C. T. (1972). Eskimo housing as planning cultural change. Ottawa: Department of Indian Affairs and Northern Development.

Truth and Reconciliation Commission of Canada. (2015). Truth and reconciliation commission of Canada: Calls to action. Retrieved from http://www.trc.ca/ websites/trcinstitution/File/2015/Findings/Calls_to_ Action_English2.pdf

Ugarte, M. (2014). Ethics, discourse, or rights? A discussion about a decolonizing project in planning. Journal of Planning Literature, 29(4), 403-414.

Van Nostrand, J. (2014, September 8). If we build it, they 
will stay. The Walrus, pp. 34-39.

Walker, R. C. (2006). Searching for Aboriginal/Indigenous self-determination: Urban citizenship in the Win- nipeg low-cost-housing sector, Canada. Environment and Planning $A, 38,2345-2363$.

\section{About the Author}

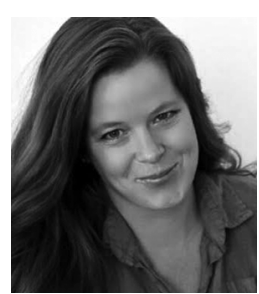

Shelagh McCartney is an Assistant Professor in the School of Urban and Regional Planning at Ryerson University (Toronto, Canada). Her work, both academically and as a licensed architect, focuses on urbanization, housing and community development; recognizing that planning and architecture are part of complex networks and histories within communities. Her work with First Nations communities is based on partnership and mutual understanding in creating designs reflective of local values. 